Bangladesh J. Zool. 41(1): 97-103, 2013

\title{
PREVALENCE OF TRICHURIS TRICHIURA AMONG THE CHILDREN OF AGE UNDER FIVE YEARS
}

\author{
Tahmina Ahmed, Hamida Khanum and Anwar Hossain ${ }^{1}$ \\ Department of Zoology, University of Dhaka, Dhaka-1000, Bangladesh
}

\begin{abstract}
A total of 2880 stool samples of children (under 5 years old) were examined during January to June 2006. The rate of infection of Trichuris trichiura was $5.27 \%$. The highest prevalence was $10.18 \%$, among the children of $2-3$ years and none (zero) among 0-1 years. The male children $(6.11 \%)$ were more infected than the female $(4.27 \%)$. The mixed infection of $T$. trichiura and Ascaris lumbricoides (26.31\%) was higher than the T. trichiura and Giardia sp. (10.52\%). The highest rate of infection (6.74\%) was found in June and lowest in January (4\%).

Key words: Prevalence, Trichuris trichiura, children and risk factors.
\end{abstract}

\section{INTRODUCTION}

Infection of nematodes is a major public health problem in the developing and underdeveloped countries including Bangladesh. It is cosmopolitan due to poor hygienic habits and living conditions of the majority of the population. Trichuris trichiura is one of the nematodes that cause a disease Trichuriasis in man especially in children. These are soil-transmitted nematodes that easily transfer to the children. In Bangladesh, the infection of helminthes causes high degree of morbidity and mortality of infants and children. WHO (1994) estimated that approximately 1.4 billion, 1.2 billion and 1 billion persons are currently infected with Ascaris lumbricoides, hookworm (Ancylostoma duodenale/Necator americanus) and $T$. trichiura respectively.

Bangladesh is mostly a plain land and embedded with rivers and canals. The soil humidity and temperature contributes a lot towards parasitic infection. Several studies showed that intestinal parasitic infections are present all the time everywhere in this country (Nuruzzaman and Huda 1974, Muttalib et al. 1975, and Shakur and Ehsan 1993). Helminthiasis is a most common health problem in the tropics because the environment is favorable for the transmission of the helminthiasis in the community. In Bangladesh, among the helminthes and protozoan parasites (A. lumbricoides, A. duodenale, T. trichiura, Enterobius vermicularis and Entamoeba histolytica, Giardia sp.) are common (Kuntz 1960, Banu et al. 2003, Khanum et al. 2010). A multi-center survey of more than 25000 people revealed that whereas the overall prevalence of gastro-intestinal

${ }^{1}$ ICDDR,B, Mohakhali, Dhaka 1212, Bangladesh. 
helminthiasis in Malaysia was 36.6\%, the infection prevalence exceeds $50 \%$ in urban slum populations (Kan 1982). Ahmed and Talukder (2002) found the prevalence (39\%) of T. trichiura among the children (9-16) from rural and urban areas of Bangladesh. Opara et al. (2007) found $1.6 \%$ prevalence of $A$. lumbricoides and $T$. trichiura combination among the school children.

Children under 5 years seem to be the most vulnerable of all age groups. Helminthiasis especially trichuriasis in children under 5 years of age seemed to be directly related to the mother's knowledge about cleanliness and hygiene. In Bangladesh it was found that $56-90 \%$ of $4-13$ years old children harboring A.lumbricoides and $60 \%$ of $1-40$ years old people suffer from E. vermicularis infection (D'Silva et al. 2003).

Since children are at the highest risk of morbidity due to trichuriasis, these findings suggest that helminthiasis in children may be of particular significance to the health of urban slum populations. There are few studies on the children of lower than five years old in a well known hospital like ICDDR, B of Dhaka city. So it is expected that the information obtained from the present study will add more intervention in research.

The aim of the study was to observe the infection of Trichuris trichiura among the children of lower than 5 years old as out-patient in ICDDR, B hospital and to provide definite information about the rate of infection of intestinal parasites in a hospital of urban area. The study was also carried out to find out the distribution of intestinal parasites in relation to age and sex, to obtain knowledge and impression about socio-economic condition of the patients of that hospital.

\section{MATERIAL AND METHODS}

The study was conducted in the Pathology Laboratory of the ICDDR, B hospital at Mohakhali in Dhaka city. A total of 2880 stool samples were examined. The different age groups of the children were: 0-1 years, 1.1-2 years, 2.1-3 years, 3.1-4 years and 4.1-5 years.

The faecal specimens were examined under the microscope for ova of $\mathrm{T}$. trichiura, A. lumbricoides and Giardia lamblia. The methods mostly used in this investigation were Iodine smear with direct saline and iodine mount, Formaldehyde-Ether concentration method.

A drop of saline solution $(0.85 \%)$ was placed in the center of a clean slide and about $2 \mathrm{mg}$ of faeces was mixed with it by a stick and covered with cover slip. (Routine examination of Stool, Clinical Laboratory, ICDDR,B hospital. Reference: 1(PP 113-115). Finally it was examined under microscope. The 
findings were confirmed by the help of Neva and Brown (1994), Cheesbrough (1987) and Chatterjee (2004).

\section{RESULTS AND DISCUSSION}

The highest prevalence $(10.18 \%)$ was found at the children of age group 4$5 y e a r s$ and the lowest (zero) at 0-1years among all five groups. It implies that the rate of infection was increasing steadily with the age group (Table 1).

Table 1. Distribution of Trichuris trichiura infection according to the age of children

\begin{tabular}{lccc}
\hline $\begin{array}{l}\text { Age group } \\
\text { (years) }\end{array}$ & Samples examined & Infected & $\begin{array}{c}\text { Prevalence } \\
(\%)\end{array}$ \\
\hline $0-1$ & 420 & 0 & 0 \\
$1.1-2$ & 585 & 8 & 1.36 \\
$2.1-3$ & 568 & 24 & 4.22 \\
$3.1-4$ & 600 & 48 & 8 \\
$4.1-5$ & 707 & 72 & 10.18 \\
Total & 2880 & 152 & 5.27 \\
\hline
\end{tabular}

The male children (1570) were infected more than the female (1310). It was clearly observed that the prevalence were significantly different among the two groups (Table 2).

Table 2. Distribution of Trichuris trichiura infection according to the sex of children

\begin{tabular}{lccc}
\hline $\begin{array}{l}\text { Sex of } \\
\text { children }\end{array}$ & Samples examined & Infected & $\begin{array}{c}\text { Prevalence } \\
(\%)\end{array}$ \\
\hline Male & 1570 & 96 & 6.11 \\
Female & 1310 & 56 & 4.27 \\
\hline
\end{tabular}

The highest prevalence in male and female was $10 \%$ and $7.14 \%$ at the age group of 4-5years and 3-4 years respectively. A noticeable difference was found in case of the parasitic infection between the age groups of male and female whereas a strong similarity was observed in the lowest prevalence (zero) both in male and female children at the age of 0-1 years. The rate of infection was always higher in male than female in all age groups (Table 3). Outdoor patients were less $(5.2 \%)$ infected than the indoor patients $(6.24 \%)$ (Table 4$)$.

The number of ova in every $2 \mathrm{mg}$ of stool indicates how much infected the children were. Among 152 infected children, 84 showed low infection due to the presence of one or more than one ova per $2 \mathrm{mg}$ of stool. Likewise, 44 children were with moderate infection $(2+)$ and 24 showed high $(3+)$ infection. 
Table 3. Distribution of Trichuris trichiura infection according to various age groups of male $(n=1570)$ and female $(n=1310)$ children

\begin{tabular}{lcccccc}
\hline \multirow{2}{*}{$\begin{array}{l}\text { Age group } \\
\text { (years) }\end{array}$} & $\begin{array}{c}\text { Sample } \\
\text { examined }\end{array}$ & Infected & $\begin{array}{c}\text { Prevalence } \\
(\%)\end{array}$ & $\begin{array}{c}\text { Sample } \\
\text { examined }\end{array}$ & $\begin{array}{c}\text { Infected } \\
\text { Pale children }\end{array}$ & $\begin{array}{c}\text { Prevalence } \\
(\%)\end{array}$ \\
\hline 0-1 years & 260 & 0 & 0 & 160 & 0 & 0 \\
1.1- 2years & 280 & 8 & 2.85 & 305 & 8 & 2.62 \\
2.1-3 years & 270 & 16 & 5.92 & 298 & 12 & 4.02 \\
3.1-4 years & 320 & 28 & 8.75 & 280 & 20 & 7.14 \\
4.1-5 years & 440 & 44 & 10 & 267 & 16 & 6 \\
\hline
\end{tabular}

Table 4. Distribution of Trichuris trichiura infection according to the Local ID in ICDDR, B Hospital

\begin{tabular}{llccc}
\hline Local ID & Location & $\begin{array}{c}\text { Sample } \\
\text { examined }\end{array}$ & Infected & $\begin{array}{c}\text { Prevalence } \\
(\%)\end{array}$ \\
\hline 002 & Outpatients & 2075 & 108 & 5.20 \\
001 & Inpatients & 705 & 44 & 6.24 \\
\hline
\end{tabular}

Considering all of the age groups, most of the children were suffering from low infection (75\% at the age group of 1-2 years). On the other hand 2-3 years of children were equally (42.85\%) suffered with low and moderate infection. A remarkable change was noticed at the age group of 3-4 years where half $(50 \%)$ of the children were highly infected with $T$. trichiura (Table 5).

Only one protozoan parasite, Giardia lamblia and one nematode parasite A. lumbricoides other than $T$. trichiura were identified during the present investigation. The prevalence of $T$. trichiura and $A$. lumbricoides parasite combination $(26.31 \%)$ was more than double compared with that of G. lamblia and $T$. trichiura parasite combination (10.52\%). The rate of single infection of $T$. trichiura was the highest (63.15\%) among those three groups of infection. (Fig. 1)

Table 5. Distribution status of the Trichuris trichiura infection among the children of different age group

\begin{tabular}{lccccccc}
\hline $\begin{array}{l}\text { Age group } \\
\text { (year) }\end{array}$ & $\begin{array}{c}\text { Total } \\
\text { sample } \\
\text { infected }\end{array}$ & $\begin{array}{c}\text { No. of } \\
\text { children with } \\
\text { low infection }\end{array}$ & $\begin{array}{c}\text { Pre- } \\
\text { valence } \\
\%\end{array}$ & $\begin{array}{c}\text { No. of children } \\
\text { with moderate } \\
\text { infection }\end{array}$ & $\begin{array}{c}\text { Pre- } \\
\text { valence } \\
\%\end{array}$ & $\begin{array}{c}\text { No. of highly } \\
\text { infected } \\
\text { children }\end{array}$ & $\begin{array}{c}\text { Pre- } \\
\text { valence } \\
\%\end{array}$ \\
\hline $0-1$ & 0 & 0 & 0 & 0 & 0 & 0 & 0 \\
$1.1-2$ & 16 & 12 & 75 & 4 & 25 & 0 & 0 \\
$2.1-3$ & 28 & 12 & 42.85 & 12 & 42.85 & 4 & 14 \\
$3.1-4$ & 48 & 24 & 50 & 16 & 33 & 8 & 50 \\
$4.1-5$ & 60 & 32 & 53.33 & 16 & 26.66 & 12 & 20 \\
\hline
\end{tabular}

Regarding mixed infestation with the age groups of the children, $A$. lumbricoides and $T$. trichiura combination was found to be overwhelmingly dominant in all age groups and the highest prevalence $(57.14 \%)$ was found in 2 - 
3 years old children. This was in stark contrast when $25 \%$ of children were infected with A. lumbricoides $+T$. trichiura at the age group of 1-2 years and 3-4 years, no concurrent infection of Giardia $+T$. Trichiura prevailed at the same age group (Table 6).

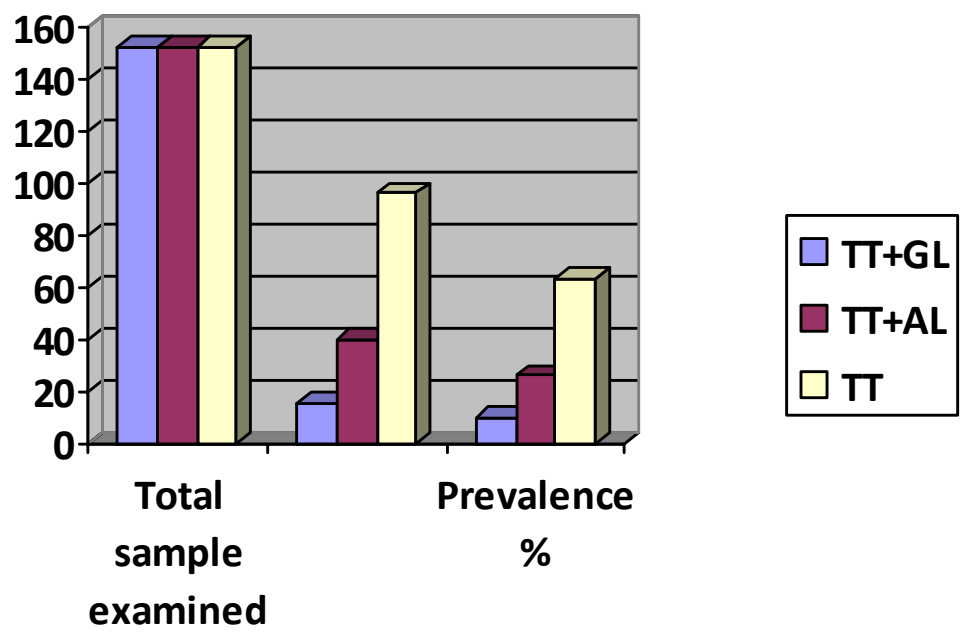

Fig. 1. Prevalence of single and concurrent infection as observed during the study period

The problem of helminth infection are increasing day by day in underdeveloping countries including Bangladesh. It is because of the hygienic condition of rural areas. People of these areas are deprived of proper sanitation. Illiteracy is the main reason for lack of awareness. But the people of high society of urban areas are free from these problems. People who are well-off and are capable of bearing high payments, come in such an expensive hospital for stool examination. The efforts of paying high payment can give an impression about their high economic condition.

Table 6. Distribution of concurrent infection according to age group

\begin{tabular}{llllll}
\hline \multirow{2}{*}{$\begin{array}{l}\text { Age group } \\
\text { (years) }\end{array}$} & $\begin{array}{l}\text { Total } \\
\text { sample }\end{array}$ & \multicolumn{2}{l}{ Infected by TT+G } & \multicolumn{2}{l}{ Infected by TT+AL } \\
\cline { 3 - 6 } & 0 & $\mathrm{~N}$ & $\mathrm{P}$ & $\mathrm{n}$ & $\mathrm{P}$ \\
\hline $0-1$ & 16 & 0 & 0 & 0 & 0 \\
$1.1-2$ & 28 & 0 & 0 & 4 & 25 \\
$2.1-3$ & 48 & 4 & 14.8 & 16 & 57.14 \\
$3.1-4$ & 60 & 0 & 0 & 12 & 25 \\
$4.1-5$ & 8 & 13.33 & 8 & 13.33 \\
\hline
\end{tabular}

$\mathrm{AL}=$ Ascaris lumbricoidis,$\quad \mathrm{TT}=$ Trichuris trichiura,$\quad \mathrm{G}=$ Giardia, $\mathrm{P}=$ Prevalence, $\mathrm{n}=$ number 
A Brazilian study by Ferreira (2001) reported overall prevalence of $T$. trichiura $5 \%$ which was almost similar $(5.27 \%)$ to our present study. On the other hand prevalence of single parasitic infestation was reported by Khanum et al. (2001) and observed $15.30 \%$ T. trichiura among the 2-16 years of subjects from lower income families of Dhaka city. This value was higher than our studies.

Huq and Sheikh (1976) carried out a study on intestinal parasites in detail. Out of 1500 children of different age groups up to 15 years and calculated their various distributions and correlating factors. Gross prevalence was $65.80 \%$ and both sexes were equally infected.

In the present study, the extent of double parasitic infection was also lower $(26.31 \%)$ than that of single infection of $T$. trichiura $(63.15 \%)$ among 38 infected children. Khanum et al. (1999) reported the prevalence $(23.5 \%)$ of $T$. trichiura and the mixed infection of $A$. lumbricoides and T. trichiura were $15.25 \%$ among the 400 children of four slum areas in Dhaka city. The concurrent infection of T. trichiura and Giardia was lowest (zero) at the age of 0-1 years old children. According to (EPA 1998), besides adults, children are highly susceptible whereas breast-fed infants (less than 6 months of age) are not likely to be infected.

\section{LITERATURE CITED}

AHMED, S. and TALUKDER, K.K. 2002. Knowledge, attitude and practice of environmental sanitation and personal hygiene of school children in rural Bangladesh. Environmental threat to the health of children: Hazards and vulnerability, Bangkok, Thailand 3-7.

BANU, H., D' SILVA, J. and ISLAM, N. 2003. Epidemiological factors and pinworm infection in children. Bangladesh J. Zool. 31: 243-246.

CHATTERJEE, K.D. 2004. Parasitology (Protozoology and Helminthology) in relation to clinical medicine. Chatterjee Medical Publisher, Calcutta. 238 p.

CHEEsBrough, M. 1987. Medical Laboratory Manual for Tropical Countries. Blackworth Co Publishers. 570 p.

D'SILVA, J., BANU, H. and ISLAM, N. 2003. Pinworm infection in children and their personal habits. Dhaka Univ. J. Biol. Sci. 12:193-194.

EPA (ENVIRONMENTAL PROTECTION AGENCY). 1998. Giardia: Human health criteria document. United States Environmental Protection Agency.

FERREIRA, H. 2001. The risk of Ascaris lumbricoides infection in children as an environmental health indicator to guide preventive activities in Caparao and Alto-caparao, Brazil WHO Bull 80: 40-46.

HUQ, N. and SHEIKH, A. 1976. Incidence of intestinal parasite in children of different socioeconomic population of Dhaka city. B.M.R.C. Bull. 11(1):20-26.

KAN, S.P. 1982. Soil-transmitted helminthiasis in Selan-gor, Malaysia. Medical journal of Malaysia 37:180-190. 
KHANUM, H., CHAWDHURY, S., and BHUIYAN, Z.J. 1999. Infestation of three intestinal worms in children of three selected areas, Bangladesh, Department of Zoology, University of Dhaka, 1000, Bangladesh. Pakistan J. Zool. 31(4): 391-396.

KHANUM, H., ISLAM, M.N. and NAHAR, K.N. 2001. Intestinal nematode infection among children of lower income group employers in Dhaka city. Bangladesh J. Zool. 27:177-183.

KHANUM, H., ISLAM, M.R. and PARVIN, S. 2010. Occurrence of eggs and larvae of gastrointestinal nematodes in nails of street inhabitants in Dhaka city. J. Life Eart. Sci. 5:75-79.

KUNTZ, R.E. 1960. Intestinal protozoa and helminthes in School going children of Dhaka city, Am J Trop. Med. Hyg. 9:168-174.

MUTTALIB, M.A., ISLAM, N., GHANI, J.A. KHAN, K., AZIZULLAH, A. and ISLAM, B. 1975. Intestinal parasites in the University of Dacca student. J. Trans. Med. Hyg. 78: 10-11.

NEVA, F.A. and BROWN, H.W. 1994. Basic Clinical Parasitology. Prentice Hall International Inc. USA. pp. 356.

NURUZZAMAN, M. and HUDA, Q. 1974. Parasitic infestation in gastrointestinal tract disorders. Bangladesh Med. J. 2:119-123.

OPARA, F.N., UDOYE, A.A., OKERE, P.U., OSUALA, F.O.U. and IWUALA, M.O.E. 2007. The prevalence of intestinal helminth infections in primary school children in Owerri municipality, Imo state, Nigeria. J. Parasitic Dis. 31:44-48.

SHAKUR, M.S. and EHSAN, M.A. 1993. Intestinal parasites: a frequent association and contributing factor of loose motion in malnourished children. Bangladesh J. Child. Health 17:10-13.

WHO (WORLD HEALTH ORGANIZATION). 1994. Report of the WHO informal consultation on hookworm infection and anemia in girls and women.WHO/CTD/SIP/96.1.

(Manuscript received on 5 January 2013; revised on 15 June 2013) 